\title{
Cultura e identidade: os desafios para o desenvolvimento local no assentamento Aroeira, Chapadão do Sul, MS
}

Culture and identity: the challenges for the local development in the Aroeira nesting, Chapadão do Sul, MS

Culture et identité: les défis pour le développement local du replacement Aroeira au Chapadão do Sul, MS

Cultura e identidad: los desafíos para el desarrollo local en el asentamiento Aroeira, Chapadão do Sul, MS

\author{
Maria Augusta de Castilho* \\ Mauro Mallmann Arenhardt** \\ Cleonice Alexandre Le Bourlegat***
}

Recebido em 10/8/2007; revisado e aprovado em 12/12/2008; aceito em 20/1/2009

\begin{abstract}
Resumo: Este artigo quer mostrar a realidade do Assentamento Aroeira, no município de Chapadão do Sul, Estado de Mato Grosso do Sul, por meio da cultura e identidade, como desafios para o desenvolvimento local. O objetivo é verificar se a cultura e a identidade interferem nos relacionamentos comunitários e interpessoais. O estudo foi iniciado com a análise da realidade dos assentados, a partir das concepções culturais e dos relacionamentos que são estabelecidos com os vizinhos e demais moradores do Assentamento. Levou-se em consideração a participação comunitária, a cooperação, a solidariedade e a confiança via coleta de informações junto aos moradores por meio de entrevistas, formulários e questionários. Detectou-se a dificuldade dos assentados de manterem relacionamentos confiáveis entre si. Esta é uma das causas, atribuída à diversidade cultural de que é formado o Assentamento Aroeira, como também, as experiências das pessoas em viver em comunidade. Tais dificuldades se tornaram visíveis na organização comunitária e nos relacionamentos entre si, refletindo na falta de confiança, solidariedade, cooperação e identidade cultural local. Conclui-se que os assentados buscam uma melhora na qualidade de vida, mas precisam ser incentivados por ações capazes que possam promover relacionamentos mais confiáveis, uma vez que o modelo proposto não possibilita uma boa organização comunitária que é imprescindível para o desenvolvimento local.
\end{abstract}

Palavras-chave : Cultura. Identidade. Comunidade.

Abstract: The research looked for to show the Aroeira Nesting in the city of Chapadão of the South, State of Mato Grosso of the South, by means of the culture and identity, as challenges for the local development. The objective is to verify if the culture and the identity intervene with the communitarian and interpersonal relationships. The study it was initiated with the analysis of the reality of the seated ones, from the cultural conceptions and the relationships that are established with the excessively living neighbors and of the Nesting. The communitarian participation, the cooperation was taken in consideration, solidarity and the confidence saw collection of information participation, the cooperation was taken in consideration, solidarity and the confidence saw collection of information together to the inhabitants by means of interviews, forms and questionnaires. It was detected difficulty of the seated ones to keep trustworthy relationship between itself. This is one of the causes, attributed the cultural diversity of that the Aroeira Nesting is formed, a also, the inexperience of the people in living in community. Such difficulties if had become visible in the communitarian organization and the relationships between itself, reflecting in the reliable lack, solidarity, cooperation and local cultural identity. One concludes that the seated ones search an improvement in the quality of life, but, they need to be stimulated by capable actions that can promote relationships more trustworthy, a time that, the considered model does not make possible a good communitarian organization that is essential for the local development.

Key-words: Culture. Identy. Community.

Résumé: Cet article veut montrer la réalité du Replacement Aroeira dans le municipe de Chapadão do Sul, État du MatoGrosso do Sul, par la culture et l'identité, comme défis pour le développement local. L'objectif est de vérifier si la culture et l'identité interfèrent dans les rapports communautaires et interpersonnels. L'étude a commencé par l'analyse de la réalité des replacés, à partir des concepts culturels et des relations qui sont établies avec les voisins et autres habitants du replacement. Il a été considéré la participation communautaire, la coopération, la solidarité et la

\footnotetext{
${ }^{1}$ Doutora em História Social.Professora e Vice-Coordenadora do Programa de Pós-Graduação em Desenvolvimento Local - Mestrado Acadêmico. Professora do Curso de História da Universidade Católica Dom Bosco - UCDB. Email: maugusta@ucdb.br.

${ }^{2}$ Graduado em Filosofia pela Fundação Educacional de Brusque, FEBE, SC. Professor de Ética e Filosofia, Sociologia, Antropologia e Introdução às Ciências Sociais pela Faculdade de Chapadão do Sul, FACHASUL, nos cursos de Administração e Ciências Contábeis. Funcionário Público de Chapadão do Sul, exercendo o cargo de Diretoradjunto das Escolas Rurais. Mestre em Desenvolvimento Local pela Universidade Católica Dom Bosco - UCDB, MS. E-mail: mauroare@hotmail.com.

${ }^{3}$ Doutora em Geografia Humana. Professora e Coordenadora do Programa de Pós-Graduação em Desenvolvimento Local - Mestrado Acadêmico. Professora do Curso de Geografia da Universidade Católica Dom Bosco - UCDB. Email: le-bourlegat@uol.com.br.
} 
confiance par une collecte d'informations auprès des habitants à l'aide d'entrevues, de formulaires et questionnaires. Il a été détecté la difficulté que les replacés ont dans les relacions de confiances entre eux. Celle-ci est une des causes attribuée à la diversité culturelle existante dans le Replacement Aroeira, ainsi que l'expérience de vie en communauté par les personnes. Telles difficultés deviennent visibles dans l'organisation communautaire et les relations qu'ils ont entre eux, ce qui reflète dans le manque de confiance, de solidarité, de coopération et d'identité culturelle locale. En conclusion, l'étude montre que les replacés recherchent une amélioration de qualité de vie, mais ils ont besoin d'être stimulés par des actions capables de promouvoir des relations de confiances, une fois que, le modèle proposé ne permet pas une bonne organisation communautaire qui est indispensable pour le développement local.

Mots-clés: Culture. Identité. Communauté.

Resumen: Este artículo desea mostrar la realidad del Asentamiento Aroeira en el municipio de Chapadão do Sul, Estado de Mato Grosso do Sul, por medio de la cultura e identidad, como desafíos para el desarrollo local. El objetivo es verificar si la cultura y la identidad interfieren en las relaciones comunitarias e interpersonales. El estudio fue iniciado con el análisis de la realidad de los asentados, a partir de las concepciones culturales y las relaciones que son establecidos con los vecinos y demás habitantes del Asentamiento. Se llevó en consideración la participación comunitaria, la cooperación, la solidaridad y la confianza vía colecta de informaciones junto a los habitantes por medio de entrevistas, formularios y cuestionarios. Se detectó la dificultad de los asentados de mantener relaciones confiables entre sí. Esta es una de las causas, atribuida a la diversidad cultural de que es formado el Asentamiento Aroeira, como también, las experiencias de las personas que viven en comunidad. Tales dificultades se hicieron visibles en la organización comunitaria y en las relaciones entre sí, reflejándose en la falta de confianza, solidaridad, cooperación e identidad cultural local. Se concluye que los asentados buscan una mejora en la calidad de vida, pero necesitan ser incentivados por acciones capaces que puedan promover relaciones más confiables, una vez que, el modelo propuesto no posibilita una buena organización comunitaria que es imprescindible para el desarrollo local.

Palabras clave : Cultura. Identidad. Comunidad.

\section{Introdução}

O desenvolvimento local é entendido como um processo de transformação, que envolve o ser humano como o principal beneficiário dessa mudança, numa perspectiva de melhoria da qualidade de vida de uma coletividade ou grupo de pessoas que fazem parte de uma comunidade.

A conquista de um pedaço de terra pelas famílias do Assentamento Aroeira é o início do processo de luta contra a pobreza e da sua própria sustentabilidade econômica, que as remete a novos desafios de vida e de organização social.

A questão norteadora da pesquisa está nas dificuldades de relacionamentos entre as pessoas do Assentamento Aroeira, com o propósito de compreender as dificuldades de organização desses moradores. A pesquisa tinha como propósito estudar a cultura e a identidade das pessoas que formam o agrupamento comunitário, destacando-se os relacionamentos sociais e a organização geofísica, comunitária e socioculturais das pessoas em torno de objetivos comuns.

Na presente proposta de estudo, utilizou-se o método qualitativo, no intuito de entender os fenômenos sociais que caracterizam a organização social e comunitária dos moradores do Assentamento Aroeira, município de Chapadão do Sul, voltado para a ação subjetiva e objetiva das pessoas no viver e entender o cotidiano que se reflete num agir e proceder em sociedade. Para tanto, foram utilizados como métodos de investigação, a observação, entrevistas e formulários.

O olhar voltou-se, ainda, para a ação subjetiva das pessoas que ali se encontram, observando o seu cotidiano, composto de atributos espirituais, intelectuais; como também o modo de vida, os sistemas de valores, as tradições e crenças que determinam o seu agir e comportamento.

\section{Desenvolvimento local, cultura, comunidade e capital social}

O desenvolvimento local parte da perspectiva da valorização humana como sujeito de seu próprio desenvolvimento. A práxis do desenvolvimento pode ser entendida como o exercício para uma ação mais efetiva que envolve o indivíduo por meio da práxis comunitária na qual se encontra face a face com a comunidade. Assim, o indivíduo como ser social que pertence a uma classe ou grupo social, tem um espaço em que pode se exprimir, argumentar, criticar, denunciar, dialogar, exigir, reivindicar e transformar a sua realidade.

Uma das características do Desenvolvimento Local proposta por diversos autores leva a entender que se trata de um processo dinamizador da sociedade para melhorar a 
qualidade de vida da sua comunidade, contribuindo com a emergência de novas formas de produzir e compartilhar. O desenvolvimento local é um processo de transformação social, cultural, econômico e político em que os maiores beneficiários serão os indivíduos de uma sociedade.

Com efeito:

É um processo de transformação econômica, política e social, através da qual o crescimento do padrão de vida da população tende a tornar-se automático e autônomo. Trata-se de um processo social global, em que as estruturas econômicas, políticas e sociais de um país sofrem contínuas e profundas transformações (PEREIRA apud ÁVILA , 2001, p. 20).

Segundo Claxton (1994), o desenvolvimento só pode prosperar quando está fundamentado na cultura e nas tradições de um povo ou coletividade, porque é um processo vinculado aos valores de cada sociedade e que exige ao mesmo tempo uma participação ativa das pessoas e indivíduos que são os autores e os beneficiários do mesmo. De acordo com Kliksberg (2001, p. 140), "a cultura pode ser um instrumento formidável de progresso econômico e social".

De acordo com Marques e Martin (2001, p. 58), o desenvolvimento local necessita levar em consideração "a identidade cultural nas estratégias de desenvolvimento local, deslocando o eixo do econômico para o bem estar e satisfação das necessidades humanas e, por conseguinte, melhoria da qualidade de vida, a partir do protagonismo dos agentes locais".

Sendo o desenvolvimento local um processo de transformação social, cultural, econômica e política, passa a adquirir dimensões maiores do que imaginamos e que se apresentam de forma complexa e dinâmica dentro de uma realidade local e global. É importante ressaltar que o ser humano passa a ser o agente principal do desenvolvimento através da sua participação direta e ativa. Esse desenvolvimento ocorrerá efetivamente a partir do momento que se tomar consciente da importância como sujeito da sua própria história e da capacidade de poder influenciar o seu entorno, ao desvelar as suas capacidades, competências e habilidade de se organizar a partir das suas limitações geofísicas.
O desenvolvimento pretende ser uma resposta às perguntas sobre como podemos diminuir as desigualdades sociais e uma forma de proporcionar uma melhor distribuição da riqueza entre países desenvolvidos e subdesenvolvidos ou, ainda, o desenvolvimento, no caso de países como o Brasil. Nesse sentido, pretende ser uma alternativa para as comunidades locais serem os próprios gestores de seu desenvolvimento, não ficando presas às políticas governamentais que são concebidas de forma vertical, não levando em consideração as relações horizontais e as particularidades locais de uma comunidade ou grupo cultural.

O Desenvolvimento Local é uma das alternativas mais viáveis para se proporcionar o desenvolvimento numa comunidade, pois, ao gerar condições favoráveis para a cooperação, a ajuda mútua e ações conjuntas criam fundamentos básicos para o início de um processo de organização e planejamento em torno de objetivos comuns. Godard et al. (1987, p. 139) define o Desenvolvimento Local como base para que esse processo de organização aconteça por meio da cooperação.

Uma das chaves do desenvolvimento local reside na capacidade de cooperação de seus atores. Também é conveniente particular a análise das formas de cooperação institucional ou voluntária que se produzem entre eles contanto que o objetivo seja o desenvolvimento.

Considerando que cada povo ou grupo social tem as suas mais diversas formas de criatividade e dinamismo, é a própria cultura que pode dar credibilidade de existência e identidade a um grupo de pessoas ou comunidade.

De acordo com Pierre (apud CLAXTON, 1994, p. 7), a cultura pode ser definida como uma "interpretação global da natureza, um sistema total para compreender e mudar o mundo. A cultura abarca todas as expressões produtivas do ser humano, tecnológicas, econômicas, artísticas e domésticas. Implica uma relação sistemática entre cada aspecto da vida, tal como esta é vivida".

A cultura pode ser entendida como uma totalidade integrada em uma sociedade como um sistema de relações sociais. Esta se apresenta de forma dialética, por meio dos 
valores básicos e fundamentais que constituem uma cultura e as dinâmicas que ela envolve. A construção dessa realidade, também se torna fundamental e necessária para o desenvolvimento. Como todo desenvolvimento implica mudanças, supõe-se que essas transformações requerem elementos que possam ser considerados estáticos ou fundamentais que são um princípio norteador para essa mudança ocorrer.

Pode-se, assim, entender a cultura como um conjunto de atividades e crenças de uma sociedade ou grupo, que se compõe por aspectos estáticos e dinâmicos. Podemos complementar esse conceito, reforçando que a "cultura é o conjunto de soluções originais que um grupo de seres humanos inventa, a fim de se adaptar ao meio ambiente natural e social" (KASHIMOTO; MARINHO; RUSSEFF, 2002, p. 35).

Toda cultura passa por processos de construção de significados culturais, sociais e econômicos que são internalizados pelos próprios membros que fazem parte do grupo ou sociedade e por meio deles vão construindo a sua identidade.

Observa-se que cada sociedade possui as suas particularidades de organização e de satisfação das suas aspirações; logo, pode-se entender que essas particularidades são fundamentais para a identificação ou, ainda, uma necessidade que o sujeito tem de ser conhecido perante os outros de forma distinta, por isso a importância da valorização dos aspectos culturais que são mais significativos para sua identificação cultural.

Ressalta-se, ainda, a necessidade da valorização da cultura como um aspecto importante para o desenvolvimento, pois só assim as pessoas podem ter mais facilidade de encontrar soluções criativas para os problemas enfrentados no seu cotidiano de vida, fortalecendo ainda mais sua identidade e valores.

A cultura atua como fermento do desenvolvimento, pois é ela que gera e transmite os valores de geração em geração, tornando necessário conhecer a realidade cultural de um grupo social local em profundidade, porque é a identidade cultural que rege a "permanente evolução dos sentimentos e das maneiras de perceber as coisas que caracterizam todas as comunidades em um momento dado" (HERMET, 1999, p. 16).

O surgimento do Assentamento Aroeira teve como fundamento básico a distribuição de terra a famílias vindas de vários lugares da região como: Chapadão do Sul, Cassilândia, Costa Rica e ainda de outros lugares em menor proporção.

A procedência de vários lugares demonstra características culturais, hábitos e costumes que se assemelham e simultaneamente divergem em alguns pontos, pois, como toda relação comunitária surge a partir das interações entre os indivíduos que buscam estabelecer um relacionamento ou um vínculo de compromisso, com a identidade cultural que é diferenciada na sua forma de entender e compreender a realidade externa e o mundo a sua volta.

De acordo com Tönnies (1973), nas relações comunitárias prevalece a confiança e a intimidade, fazendo com que um se sinta próximo do outro como um organismo vivo, sendo a essência da comunidade. A vida real, com a predominância do sentimento do pertencimento a um grupo, "o nós", como parte integrante dessa relação se torna uma das características fundamentais na formação de uma comunidade. "As relações de interação levam consequentemente à uma associação de seus membros que pode ser compreendida como a vida real, uma das essências da comunidade" (TÖNNIES, 1973, p. 96).

Pode-se entender que o Assentamento Aroeira não pode ser compreendido como comunidade, a partir do momento em que as relações de interação, compreensão, partilhar e solidariedade não são vistas como valores cultivados e vividos pelos moradores, onde a colaboração para um fim comum, que é a coesão social, cede espaço para o individualismo e a desunião entre os moradores. Os assentados ainda não podem ser identificados como uma comunidade em que prevalece o sentimento de pertencimento, a territorialidade, a permanência no local como condição para estabelecer o corporativismo em torno de um projeto comum, que é a identidade cultural e local.

A comunidade é uma forma de praticarmos a solidariedade e o lugar ideal para unir forças no sentido de lutar para diminuir as diferenças sociais que assolam a nossa realidade. O lugar onde compartilhamos sentimentos e valores ou buscamos a companhia 
de pessoas que pensam ou sentem as mesmas emoções; lugar em que procuramos ser solidários como uma forma de dar vida a nossa própria existência.

A comunidade passa a ser concebida como importante para se estabelecer a cooperação, a solidariedade e para a ação social e como espaço privilegiado para iniciativas de desenvolvimento local. A partir do momento que temos a individualização da sociedade e diante das constantes mudanças que ocorrem por causa da globalização, a identidade das comunidades locais passa a ser um contínuo construir, porque a realidade globalizada faz com que as pessoas busquem sempre a autoafirmação.

De acordo com Ávila (2001, p. 34), a cada dia que passa, a população se torna cada vez menos capaz de se organizar, administrar, solucionar ou pelo menos participar ativamente da resolução de seus problemas básicos. A sociedade, assim como a comunidade, passa por um processo de individualização no qual se perde o caráter coletivo das ações e das queixas ou reivindicações e, ao mesmo tempo, perdem-se os valores que são referência e servem como padrão comunitário de organização, mobilização e participação.

O capital social vem como resposta ao pensamento econômico convencional, de que a sociedade é formada por indivíduos independentes, cada um agindo de acordo com seus objetivos. O capital social passa a ser um dos componentes-chaves do desenvolvimento, destacando a cooperação, a confiança, a identidade, a comunidade e a amizade entre os indivíduos como um instrumento de solução para a ação coletiva.

Fukuyama (2000, p. 28) define o capital social "como um conjunto de valores ou normas informais comuns aos membros de um grupo, que permite a cooperação entre eles". Essa cooperação só ocorrerá se houver se estabelecido uma rede de relações sociais de confiança e honestidade.

Supõe-se que, dentro do contexto de desenvolvimento, cada vez mais se faz necessária a discussão da importância do capital social como um dos aspectos fundamentais para o desenvolvimento local acontecer. Ao se levar em consideração que cada comunidade possui suas particularidades econômicas, sociais, culturais e ambientais, essas po- derão ser um instrumento importante para o progresso econômico e social, como uma forma de valorizar as riquezas culturais e materiais que as comunidades trazem consigo por meio das tradições, hábitos, costumes cultivados ao longo da história.

De acordo com Baquero (2003), o capital social ajuda a compreender o desenvolvimento local, mas principalmente a formulação de políticas mais apropriada em termos de cultura ou civilidade e, acima de tudo, de relações e redes sociais.

Por isso, torna-se cada vez maior a necessidade de projetos que levem em consideração a valorização da identidade cultural da comunidade, suas particularidade e potencialidades como ferramentas para o Desenvolvimento local.

\section{Territorialidade, lugar, espaço e território}

Nesse caso, os agricultores do Assentamento Aroeira, que transformaram o espaço físico em um espaço social, por se apropriarem do lugar e o carregarem de sentimentos, emoções e significados, constroem um símbolo de luta, conquista e poder. A terra passou a ter um valor e significado individual e social. Conforme Tuan (1980, p. 113),

para viver o homem deve ver algum valor em seu mundo. $\mathrm{O}$ agricultor não é exceção. Sua vida está atrelada aos grandes ciclos da natureza; está enraizada no nascimento, crescimento e morte das coisas vivas; apesar de dura, ostenta uma sociedade que poucas ocupações podem igualar.

Assim, a territorialidade é o exercício de poder social, político e econômico em um contexto local ou nacional que resulta do processo de valorização do espaço geográfico, que contém relações de inclusão que constituem uma problemática do indivíduo que pertence a uma coletividade, que necessita de uma forma (lugar), de um conteúdo (significado) e da exterioridade como um sistema institucional, político e cultural (RAFFESTIN, 1993, p. 160). Os elementos que constituem essa coletividade são suscetíveis de mudanças e variações no tempo e espaço, numa constante dialética de inclusões e exclusões de relações individuais que 
pertencem a um espaço social.

Os lugares podem ser vistos como um intermédio entre o mundo e o indivíduo (SANTOS, 1996), para quem a lógica do desenvolvimento dos sistemas sociais se manifesta pela unidade das tendências opostas à individualidade e a globalidade. O local pode ser ainda o lugar em que as pessoas estão ligadas pela identidade de pertencimento, ou por atividades úteis ao desenvolvimento econômico, social e cultural da coletividade.

Podemos entender o lugar ainda como a "base territorial da convivência cotidiana, da qual a cooperação e a solidariedade se fazem pela convivência, a continuidade, as relações familiares, as emoções e sentimentos compartilhados, garantindo uma maior comunicação e uma solidariedade orgânica" (MARTN, 1996, p. 169). O local passa a ser definido como um espaço privilegiado para se estabelecerem relações de solidariedade e de parcerias entre os atores sociais, permitindo que a competição ceda lugar à cooperação.

Isto porque o lugar só pode ser compreendido em suas referências, que não são específicas de uma função do de uma forma, mas produzido por um conjunto de sentidos, impressos pelo uso. (CARLOS, 1996, p. 22)

Dessa forma, o lugar só adquire significado e sentido por meio de seu uso e ao vivido no plano imediato que pode ser apropriado pelo corpo, no cotidiano da vida.

O espaço social é resultante da constituição física dos bens e serviços e pelos indivíduos e grupos localizados que compõem uma realidade local, enfim, é a relação com a natureza e tudo o que ela contém, é a sociedade mediatizada pelo trabalho, pelas classes sociais, pelo capital e com todas as características históricas pertencentes à formação social. É o espaço organizado pelos seres humanos, de acordo com a sua capacidade de produção econômica e cultural resultante da divisão do trabalho.

Santos (1996, p. 51), amplia o conceito de espaço da seguinte forma:

É formado por um conjunto indissociável, solidário e também contraditório, de sistemas de objetos e sistemas de ações, não considerados isoladamente, ma como o quadro único na qual a história se dá [...] O espaço é hoje um sistema de objetos cada vez mais artificiais povoado por sistemas de ações igualmente imbuídas de artificialidades, e cada vez mais tendentes a finalidades estranhas ao lugar e seus habitantes.

O espaço pode ser entendido como um lugar que sempre toma novas formas, isto é, processo de reprodução da vida humana. $\mathrm{O}$ espaço aparece como produção de uma realidade concreta que se realiza no plano do cotidiano e aparece nas formas de apropriação, utilização e ocupação de um determinado lugar. Tudo o que ocorre tem a necessidade de acontecer numa objetividade concreta, por meio da qual o sujeito se situa e se realiza. "É o espaço possível de ser sentido, pensado, apropriado e vivido através do corpo" (CARLOS, 1996, p. 29).

O espaço ainda se caracteriza pela distribuição dos bens ou serviços e também pela localização física dos indivíduos ou grupos sociais em um determinado lugar. Define-se a valorização do espaço de forma distinta, de acordo com a sua ocupação e de acordo com o valor econômico ou, ainda, da cultura, no contexto global.

O território pode ser entendido como o somatório dos sistemas naturais de um determinado país ou uma determinada área, com os fatos construídos pelos homens.

A configuração territorial ou configuração geográfica tem como alicerce sua materialidade, ainda que tenha uma existência social dada pelas relações sociais. Pode-se dizer, pois, que a obra humana vai ao longo da história sendo incorporada pela configuração territorial ou geográfica. (SANTOS, 1996, p. 51)

O território existe em todas as escalas, tanto no significado da rua quanto no bairro ou comunidade. Nesse caso, o Assentamento Aroeira, por exemplo, constitui-se como território, isto é, o espaço territorial formado pela família em seu lote de terra, as estradas vicinais e a comunidade como um todo. "O território passa a ser o espaço concreto em si que é apropriado, ocupado por um grupo social" (SOUZA, 1995, p. 84). Dessa forma, são sujeitos imbuídos de poder no momento em que cada um define o território como um espaço de autonomia e de legitimidade que demanda poder, a partir das relações que estabelece com os seus vizinhos e demais membros da comunidade 
como um espaço social.

"A ocupação do território é vista como algo gerador de raízes e identidade" (SOUZA, 1995, p. 84). A identidade de um grupo social ou comunidade passa a ser entendida e compreendida a partir do seu território, isto é, de acordo com as relações que a mesma estabelece com a natureza, com o meio físico, com o patrimônio que, por meio dessas relações vai criando e estabelecendo a sua identidade sociocultural.

A partir dessa perspectiva, passa-se a entender por que os moradores do Assentamento Aroeira ainda possuem uma certa dificuldade de compreender o seu território, o seu espaço cultural, a suas raízes e a identidade, pois esse contexto começa a ser criado a partir de um certo tempo de uso desse território. De acordo com Souza (1995, p. 84), "apenas a durabilidade poderia, é claro, ser geradora de identidade socioespacial", identidade na verdade não apenas com o espaço físico, concreto, mas com o território em si, e, por tabela, com o poder de controlar esse território.

A identidade sociocultural dos membros do Assentamento Aroeira passa a ser um processo em construção por meio do seu uso da terra, sendo que o local, o espaço e o território vão ganhando sentido e significado a cada dia que passa. No entanto, poderá levar um certo tempo para que as pessoas dessa comunidade construam a sua própria identidade territorial.

Portanto, o território pode sofrer interações políticas, econômicas, sociais e culturais dos indivíduos e de grupos sociais, gerando uma malha ou rede de relações que se sobrepõem ou interpõem no espaço, que de algum modo constituem o território. $\mathrm{O}$ território se constitui pela diferenciação funcional comandada pelo princípio hierárquico que é dado pelos indivíduos ou grupos que o compõem em suas diversas ações de forma ordenada.

\section{Assentamento Aroeira: organização comunitária}

O Assentamento Aroeira está localizado no município de Chapadão do Sul, no Estado de Mato Grosso do Sul, a uma distância de $112 \mathrm{~km}$ da cidade, surgiu no ano de
2001, com a desapropriação da Fazenda Aroeira, beneficiando 59 famílias, com uma média de 32 hectares de terra para cada uma.

A composição populacional do Assentamento Aroeira pode ser caracterizada da seguinte forma: O número de pessoas que fazem parte das famílias, com 2 a 4 membros é de $61 \%$. As residências, que compõem os lares de somente 2 membros é de $27 \%$, sendo estes em maior número de residências. As residências que possuem 4 membros por lar (de família) representam um total de $22 \%$ e o percentual de pessoas que moram sozinhas é de $15 \%$, superando o número de lares compostos de até 3 membros.

A experiência de viver em comunidade passou a ser a primeira para a grande maioria dessas pessoas, a partir do surgimento do Assentamento, uma vez que a maior parte viveu no contexto sociocultural dos fazendeiros e pecuaristas da região em que os relacionamentos estão fortemente centrados no agir individual de cada um e de forma verticalizada. Esse modo de organização social não foi possível de ser aplicado aos moradores do Assentamento Aroeira, isto é, cada um vive a vida do seu modo, sem precisar do outro. Devido às circunstâncias, tornou-se necessária a criação de relacionamentos horizontalizados, e em torno de objetivos comuns relacionados por meio de produção e a busca de benefícios para todas as pessoas.

De acordo com os moradores, durante as entrevistas feitas e conversas informais, a falta de confiança entre os próprios membros da comunidade é algo muito visível e perceptível. Quando se perguntou, durante as visitas em suas casas, se confiam nas pessoas da comunidade, ou melhor, nos moradores e vizinhos do assentamento, a grande maioria respondeu, sendo que $53 \%$, diziam que confiavam pouco, $19 \%$ muito pouco e $13 \%$ não confiavam, quando envolvia assuntos relacionados à organização da comunidade ou atitudes de cooperação.

Se somarmos os que confiam pouco, muito pouco ou não confiam, teremos um percentual de $87 \%$ das pessoas que de algum modo não confiam nos membro ou vizinhos do assentamento. A ausência de credibilidade entre os moradores leva a estabelecer comportamentos personalizados, individualistas e autônomos. “Onde a desconfiança 
impera, as instituições são frágeis, e isso inviabiliza não ó a democracia como também o desenvolvimento econômico" (D'ARAUJO, 2003, p. 32).

$O$ fato de não existir o compartilhamento de valores e normas que geram confiança acaba afetando não só as relações pessoais dos moradores, mas a própria questão econômica do grupo. Segundo Fukuyama (1996), as normas, valores, costumes, hábitos possuem a sua fonte de compartilhamento no entanto, estão muito fragilizadas, sendo assim, fica difícil conceber uma melhora da confiança num espaço de tempo pequeno. Os valores tradicionais observados são os de predomínio particular, num agir individual de cada um, de acordo com seus preceitos. A história coletiva dos moradores começou a ser construída a partir de 2001, com o início do Assentamento.

A perda da obrigação moral e ajuda mútua cedeu lugar à desconfiança que está relacionada à falta de associativismo comunitário para poderem compartilhar valores e normas morais. Segundo Fukuyama (1996), a confiança só ocorre quando uma comunidade compartilha um conjunto de valores morais de forma tal que cria uma expectativa de comportamento equilibrado e honesto.

A desconfiança não gera a expectativa de que os outros vão agir honestamente ou de forma cooperativa em relação aos seus membros, quando estiverem à frente da comunidade. Revela que as pessoas do Assentamento Aroeira não confiam em seus vizinhos ou membros por terem estas expectativas frustradas durante o início da construção da comunidade, ou por não compreenderem o processo de construção de uma comunidade, baseada em valores morais que gerem confiança por parte daqueles que dela participam. A falta de honestidade e cooperativismo faz com que as pessoas olhem para os seus vizinhos com desconfiança.

A desconfiança entre os próprios membros da comunidade, o não envolvimento em questões comunitárias e a carência de boas relações com vizinhos ou membros da comunidade caracteriza o predomínio de um comportamento individualizado em que a posse da terra significou uma independência econômica e de autonomia em relação ao coletivo, que se refletiu na dificuldade de organização, prosperidade econômica e de de- senvolvimento numa perspectiva de melhora na qualidade de vida das pessoas no aspecto comunitário. Isso implica dificuldade de estabelecer uma identidade cultural que os identifique como indivíduos que fazem parte de uma determinada organização, que possuem valores, costumes e hábitos compartilhados coletivamente.

A desorganização comunitária é sentida pelas próprias pessoas ao compreenderem que, se fossem unidas, possuiriam mais força e poder para reivindicar melhorias. A falta de confiança e de boas relações, assim como a desunião é ainda influenciada por uma política econômica capitalista em que é priorizado o individualismo como forma de superar as dificuldades e os desafios da vida. São sinais de ausência dos estoques de capital social, gerando obstáculos para a organização comunitária, uma vez que o mesmo reside e se constrói a partir das relações sociais.

Uma das dificuldades observadas na pesquisa foi a capacidade de criar uma organização comunitária consistente e que inspire confiança, credibilidade, cooperação e ajuda mútua entre os membros. Essa dificuldade de se estabelecer um relacionamento interpessoal de confiança pode ser observada quando os moradores foram perguntados se confiavam nas pessoas da comunidade. Os resultados obtidos refletem um baixo índice de confiança entre os moradores e os membros da comunidade.

De acordo com Baquero (2003, p. 96):

A existência de confiança não só cria um ambiente de credibilidade e, conseqüentemente, de legitimidade, como fortalece o contrato social. A ausência desse elemento gera tensão permanente e instabilidade social que, no máximo, pode aspirar a uma democracia instável em que mecanismos de engenharia institucional não raro parecem medidas casuísticas e de descontextualizados.

Pode-se observar que os meios que ajudam a formar o capital social são vistos como fracos, já que o compartilhar comunitário se encontra limitado nas relações sociais, tidas como mínimas ou necessárias para poder estabelecer o convívio social e comunitário.

Vale ressaltar que as pessoas que compõem o Assentamento Aroeira formam grupos vindos de lugares diferentes e que se refletiu na dificuldade de integração, coope- 
ração entre os mesmos. Hoje, os grupos são constituídos em sua grande maioria por três cidades de origem: Chapadão do Sul, 55\%; Cassilândia, 28\% e Costa Rica, 9\%.

Essa diversidade cultural de que é formado o Assentamento Aroeira pode ser vista como um dos obstáculos para uma maior integração entre as pessoas, já que cada grupo de origem possui sua própria concepção cultural, de acordo com o meio em que viveu.

O que pode ser percebido, ainda, é que a grande maioria nunca participou ativamente de uma comunidade ou exerceu um cargo de liderança ou coordenação. As relações de interação social sempre aconteceram na relação de patrão-empregado, marcada pela dependência e não pela autonomia, ou seja, por formas verticalizadas.

Quando ocorreu a necessidade de se auto-organizarem, encontraram muitas dificuldades e limitações em estabelecer relacionamentos horizontalizados, em torno de objetivos comuns para o grupo, refletindo na falta de confiança e cooperação com os líderes comunitários, sendo que os mesmos tinham dificuldade em aceitar idéias ou sugestões que fossem contrárias às deles, resultando em discussões, conflito e debates sem procedência e gerando até agressões físicas, como se verifica até hoje, embora em menor proporção.

A comunidade é um dos únicos espaços privilegiados para as práticas e as iniciativas sociais.

O desenvolvimento local reforça as comunidades, dinamizando suas potencialidades, mas para que isso seja possível, é necessária a reunião de diversos fatores. O grau de educação da população é fundamental para se dispor de pessoas com condições de tomar iniciativas, assumir responsabilidade e empreender novos negócios. (MARTINELLI; JOYAL, 2004, p. 53)

Portanto, o grau de formação e a participação ativa das pessoas são tão necessários quanto os princípios e valores de confiança, solidariedade e cooperação para se poder valorizar os recursos locais e utilizar novas formas de organização social controladas democraticamente.

Tendo como uma das características do Desenvolvimento Local a valorização humana, é preciso levar em consideração os fundamentos culturais, as tradições, hábito e costumes das pessoas na construção ou criação de assentamentos rurais, pois esses valores estão implícitos nas atividades econômicas e socioculturais, no comportamento e no estilo de vida das pessoas. É o que verificamos com os moradores do Assentamento Aroeira, no sentido de buscar valorizar a prática cotidiana em que o local de convivência se transforme em um

território de identidade de solidariedade, um cenário de reconhecimento cultural e de intersubjetividade e também um lugar de representações e práticas cotidianas [...]. Necessidade de construir toda dinâmica de desenvolvimento a partir de uma identidade cultural fundamentada sobre um território de identificação coletiva e de solidariedade concreta. (GUAJARDO, 1988 apud ÁVILA, 2001, p. 26)

No sentido coletivo, a identidade sociocultural precisa ser construída, uma vez que esta se constitui a partir das relações sociais de membros de um mesmo grupo social. São essas relações que criam nas pessoas o sentimento de pertencimento a um grupo. Portanto, quanto maior for o compartilhamento das percepções comuns de uma dada realidade, maior será a interação entre si. A identidade cultural passa por uma construção de valores, hábitos, costumes e atitudes que caracterizam um grupo de pessoas ou comunidade.

A identidade cultural e a construção do espaço territorial passam a ganhar maiores significados para as pessoas do Assentamento Aroeira, a partir do momento em que se intensifica o viver e o compartilhar da vida em comum para poder superar o comportamento individualizado e a falta de confiança.

Antes de querer promover o desenvolvimento econômico, é preciso criar ou construir valores sociais que propiciem o fortalecimento do capital social e da identidade cultural local, no objetivo de dinamizar a atividade econômica, com base na pecuária.

\section{Considerações finais}

A realidade do Assentamento Aroeira evidenciou-se durante as entrevistas e preenchimento dos formulários, identificando-se a carência de uma experiência comunitária pois os relacionamentos acontecem de forma 
autônoma e independente, ausentes de qualquer compromisso mais sério de convívio social, por meio de serviços temporários ou de emprego, sendo a relação patrão-empregado uma das características principais.

Os objetivos do Desenvolvimento Local são de melhorar a qualidade de vida de uma comunidade por meio da dinamização dos processos de produção e compartilhamento, levando em consideração a identidade cultural, que está fundamentada nas tradições e valores. Ficou evidente, na pesquisa, a necessidade de estimular os moradores do Assentamento Aroeira em uma formação voltada às práticas e ações em conjunto, por meio de encontros, palestras e acompanhamentos, no sentido de propiciar às pessoas o entender e compreender a importância da união, da confiança, solidariedade e da cooperação entre eles. É fundamental que essa formação comunitária seja incluída no início do processo de organização dos assentamentos, assim como acontece com o apoio dado pelos assistentes técnicos que são disponibilizados para orientar os assentados no início da sua estruturação econômica.

A cultura e a identidade procedem a qualquer desenvolvimento econômico, pois consideradas essenciais, valorizam a construção e o estabelecimento de bases sólidas para o desenvolvimento sustentável de cada comunidade local. Se a cultura abre as portas do potencial de uma comunidade, a educação é a ferramenta que pode guiar o desenvolvimento desse potencial. Quando a comunidade reconhece o seu potencial de recursos, se torna um dos requisitos básicos para o desenvolvimento endógeno.

Destaca-se que cada grupo de assentados possui suas particularidades próprias de organização, assim como elementos culturais de acordo com cada pessoa, pois os mesmos mudam de acordo com o tempo e o espaço. A importância da cultura como elemento básico para a construção de uma identidade própria, se torna fundamental para que as pessoas possam compreender e estabelecer relacionamentos equilibrados, sendo uma base de sustentação para o desenvolvimento econômico. A identidade cultural é construída por meio de vivência social, num diálogo com os outros.

Para que o Desenvolvimento Local se torne uma prática efetiva no Assentamento
Aroeira, implica antes de tudo uma organização comunitária, para tanto é necessário criar as condições apropriadas para esse fim.

Para melhorar os relacionamentos entre os moradores do Assentamento Aroeira, é necessária uma política pública de ação, tanto do estado como do município, no sentido de cooperar via responsabilidade social para gerar oportunidades para os moradores poderem tomar suas próprias iniciativas e assumirem responsabilidades, objetivando o desenvolvimento local.

Cabe aos órgãos públicos, junto com os assentados, elaborarem projetos de desenvolvimento que ultrapassem a concepção economicista, política e assistencialista e avancem em ações que possam desenvolver o ser humano em suas concepções culturais, fortalecendo os laços de confiança e cooperação entre a comunidade.

Ao mesmo tempo, deve-se pensar em um novo modelo de assentamento rural específico para as realidades locais que possam envolver as potencialidades locais, valorizando a importância das relações humanas, baseadas na cultura e nas tradições das comunidades. Gerar desenvolvimento local de forma sustentável priorizando o bem estar social e comunitário baseado em valores como: confiança, honestidade, justiça e cooperação - é proporcionar às pessoas uma vida de melhor qualidade.

\section{Referências}

ABRAMOVAY, Ricardo. O capital social dos territórios: repensando o desenvolvimento rural. Economia Aplicada, n. 2, v. IV, p. 379-397, abril/junho, 2000. não citou no texto

ÁVILA, Vicente Fideles de (Org.). Formação educacional em desenvolvimento local: relato de estudo em grupo e análise de conceitos. 2.ed. Campo Grande. UCDB, 2001.

BAQUERO, Marcelo. Construindo uma outra sociedade: o capital social na estrutração da política participativa no Brasil. Revista de Sociologia Política, n. 21, p. 83-108, Nov., 2003.

CARLOS, Ana Fani Alessandri. O lugar no/do mundo. São Paulo: Hucitec, 1996.

CLAXTON, Mervyn. Cultura y desarrolo. Estúdio Paris: UNESCO, 1994.

D'ARAÚJO, Maria Celina. Capital social. Rio de Janeiro: Jorge Zahar, 2003.

FUKUYAMA, Francis. A grande ruptura. A natureza humana e a reconstituição da ordem social. Rio de Janeiro: Rocco, 2000. 
FUKUYAMA, Francis. Confiança. As virtudes sociais e a criação da prosperidade. Rio de Janeiro: Rocco, 1996.

GODARD, O. et al. Desarrollo endógeno y diferenciación de espacios de desarrollo: un esquema de analisis para el desarrollo local. Estudos Territoriales, Madri, n. 24, 1987.

HERMET, Guy. Cultura e desenvolvimento. São Paulo: Vozes, 1999.

KASHIMOTO, Emília M.; MARINHO, Marcelo; RUSSEFF, Ivan. Cultura, identidade e desenvolvimento local: conceitos e perspectivas para regiões em desenvolvimento. Interações - Revista Internacional de Desenvolvimento Local, Campo Grande, v. 3, n. 4, p. 35-42, 2002.

KLIKSBERG, Bernardo. Falácias e mitos do desenvolvimento local. São Paulo: Cortez, 2001.

MARQUES, Heitor Romero; MARTNS, José Carpio. Representações sociais e desenvolvimento local. In: MARQUES, Heitor Romero; RICCA, Domingos; FIGUEIREDO, Gilberto Porto (Orgs.). Desenvolvimento local em Mato Grosso do Sul: reflexões e perspectivas. 2.ed. Campo Grande: UCDB, 2001, v. 1, p. 43-63.
MARTIN, José Carpio. Perspectivas de desarrollo local. Campo Grande: UCDB, 1999. não citou no texto.

MARTINELLI, Dante Pinheiro; JOYAL, André. Desenvolvimento local e o papel da pequenas e médias empresas. São Paulo: Manole, 2004.

RAFFESTIN, Claude. Por uma geografia do poder. Trad. Maria Cecília França. São Paulo: Atica, 1993.

RIVERO-IWASITA, Alicia. Asentamientos humanos y desarrollo local. Interações - Revista Internacional de Desenvolvimento Local, Campo Grande, v. 1, n. 2, p. 37-42, 2001.

SANTOS, Milton. A natureza do espaço: técnica e tempo, razão e emoção. São Paulo: Hucitec, 1996.

SOUZA, Marcelo José Lopes de. O território: sobre o espaço e poder, autonomia e desenvolvimento. In: CASTRO. Iná Elias de. Geografia: conceitos e temas. São Paulo: Bertrand, 1995.

TÖNNIES, Ferninand. Comunidade e sociedade como entidades típico-ideais. In: FERNANDS, F. (Org.). Comunidade e sociedade. São Paulo: Nacional; Edusp, 1973.

TUAN, Yu-Tu. Topofilia. Trad. Lívia de Oliveira. São Paulo: Difel, 1980. 